Journal of Original Studies

Cilt / Volume 1, Sayı / Issue 1, 2020, pp. 31-38

E - ISSN: 2717-719X

URL: https://www.ratingacademy.com.tr/ojs/index.php/jos

DOİ:

Araştırma Makalesi / Research Article

\title{
YARALANMALI TRAFİK KAZA SAYILARININ OECD ÜLKELERİNE GÖRE INCELENMESI ${ }^{1}$
}

\author{
INVESTIGATION OF INJURY TRAFFIC ACCIDENT NUMBERS \\ ACCORDING TO OECD COUNTRIES
}

\author{
Aysen ŞİMŞEK KANDEMIR * \\ * Doç. Dr. Kocaeli Üniversitesi, TÜRKIYE, \\ e-mail: kandemir_aysen@hotmail.com \\ ORCID ID: https://orcid.org/0000-0001-5020-1183
}

Geliş Tarihi: 23 Aralık 2019; Kabul Tarihi: 16 Ocak 2020

Received: 23 December 2019; Accepted: 16 January 2020

\section{ÖZET}

Hayatımızın önemli bölümünü ilgilendiren ulaşım, aynı zamanda bir ülkenin ekonomik, sağllk, eğitim gibi pek çok boyutu ile yakından ilişkilidir. Bu boyutlar aynı zamanda ülkenin gelişmişlik düzeyi üzerinde de etkilidir. Trafik kazaları ulaşım ile birlikte ortaya çıkan önemli bir unsurdur. Ortaya çıkan bu unsurun sonuçları maddi hasarl, yaralanmalı veya ölümlü olabilmektedir. Oldukça önemli olan bu sorunun çözümü için alınan önlemler her geçen gün artmaktadır. Bu çalışmada yaralanmalı trafik kaza sayılarına göre OECD ülkeleri dikkate alınmıștır. 2017 yıl yaralanmalı trafik kazalarına göre ülkelerin kümelenmesine ve bu kümeler arasinda istatistiksel olarak anlamlı bir farkin olup olmadiğ belirlenmeye çalışılmıştır.

Anahtar Kelimeler: Kümeleme Analizi, Varyans Analizi, Trafik Kazası

\section{ABSTRACT}

Transport, which concerns the importance of our lives, is also associated with many aspects such as economic, health, and education. These dimensions also have an impact on the development level of the country. Traffic accidents are an important element associated with transportation. The consequences of this element can be materially damaged, injured or mortal. Measures taken to solve this problem, which is very important, are increasing day by day. In this study, OECD countries were taken into consideration according to the number of traffic accidents with injuries. The clustering of countries according to traffic accidents with injuries in 2017 and whether there is a statistically significant difference between these clusters were tried to be determined.

Keywords: Cluster Analysis, Variance Analysis, Traffic Accident 


\section{GİRIŞ}

Trafik kazaları halk sağlığını yakından ilgilendiren önemli bir konudur. Bu kazalar ölümlü, yaralanmalı ve maddi hasarlı olarak gruplandırılabilir (Eygü,2018: 837). Trafik kazaları halk sağlı̆̆ının yanında bir ülkenin gelişmişlik ve ekonomik refah seviyesi için de önemli bir göstergedir. Trafik kazalarının genel olarak nedenleri yaya kusuru, taşıt kusuru, yol kusuru, sürücü kusuru, yolcu kusuru olarak gruplandırılmaktadır (Alp ve Engin,2011: 68). Trafik kazalarının önlenebilesi için alınan tedbirler ve yaptırımlar her geçen gün artarak devam etmektedir.

İnsanların yaşam şartlarındaki yükselişi ile birlikte iç ve dış turizm hareketindeki artış beraberinde motorlu taşıta sahip olma arzusunu da artırmaktadır (Yurdakul vd.2017: 15). Motorlu taşıtlardaki artış istenmeyen kazalarında artmasına neden olmaktadır. Bu durum trafik kazalarına yönelik yapılan çalışmaların artmasına ve üzerinde durulması gereken önemli bir konu haline gelmesine neden olmaktadır. Yapılan çalışma, Türkiye'nin bir kümelenme durumunda hangi ülkelerle aynı kümeye düştüğünün ortaya konması açısından önemlidir.

\section{LITERATÜR TARAMASI}

Literatür taraması konuya yönelik pek çok çalışmanın yapıldığını ve konunun önemi nedeni ile yapılmaya devam ettiğini de göstermektedir. Trafik kazalarına yönelik yapılan çalışmalara ait bazı örnekler aşağıda sunulmuştur.

2018 yılında Uyurca ve Atılgan tarafından yapılan çalışmada, trafik kazaların önemli maddi ve manevi kayıplara neden olduğunu ve toplum için oldukça önemli olduğunu ortaya koymuşlardır. Aynı çalışmada kazaların en fazla yağışı havalarda, bölünmüş yollarda, Pazar günleri ve 18:00-19:00 arasında olduğu tespit edilmiştir. Bu bulgulara göre nedenler ortaya konarak çözüm önerilerinde bulunulmuştur.

Terzioğlu ve Kaya 2017 yılında ağır taşıtların karıştığı ölümlü kazalara yönelik bir çalışma yapmışlar ve yapılan çalışmada "araç hızının yol, hava ve trafiğgin gerektirdiği şartlara uymaması", "kavşak geçiş önceliğine uyulmaması" ve "manevraları düzenleyen genel şartlara uyulmaması" nedenlerinin kaza nedenleri içinde ilk sıralarda ortaya çıktığını vurgulamışlardır. $\mathrm{Bu}$ sonuçların Avrupa Kamyon Kazaları Nedensellik Araştırması Sonuçları ile paralellik gösterdiğini ifade etmişlerdir.

Özden ve Acı 2016 yılında yaptıkları çalışmada çeşitli meteorolojik parametreler ve yol durumu dikkate alınarak kazaların şiddeti arasında bir ilişki olup olmadığını araştırmışlardır. Sonuç olarak bu bilgilerin kullanılmasıyla yüksek derece doğru sonuca ulaşılabilecek tahmin modellerinin kurulabileceği vurgusu yapılmıştır.

Geymen ve Dedeoğlu 2016 y1lında coğrafi bilgi sistemlerinden (CBS) yaralanarak trafik kazalarının azaltılmasına yönelik olarak bir çalışma yapmışlardır. Bu çalışmada trafik kazalarının azaltılması için kullanılan CBS ni Kahramanmaraş örneği ile açıklamışlar ve sonuçta coğrafi bilgi sisteminin trafik kazalarının azaltılmasını ve trafik akışını sağlayacağı, arazi kullanım planlarının ve ulaşım master planlarının çok daha güvenilir ve hızlı bir şekilde yapılacağını ifade etmişlerdir.

Gökdağ ve Atalay 2015 yılında yaptıkları çalışmada, trafik eğitiminin trafik kazaları üzerindeki etkisini araştırmışlar ve eğitim eksikliğinin trafik kazalarını doğrudan etkileyen bir unsur olduğunu vurgulamışlardır.

2014 yılında Sungur ve diğerleri tarafından yapılan çalışmada trafik kazalarına ait Dünya'daki duruma bakıldığında kaza nedeni olarak en fazla sürücü yaya ve yolcu gösterilmiştir. Yine aynı çalışmada trafik kazlarına bağlı ölümlerin \%45 inin Türkiye, Brezilya, Kamboçya, Çin, Mısır, Hindistan, Kenya, Meksika, Rusya ve Vietnam'da olduğu ortaya çıkmıştır. 


\section{METODOLOJI}

Yapılan çalışmada OECD veri tabanında yer alan 2017 yılı yaralanmalı trafik kazaları verileri dikkate alınmıştır. Türkiye'nin de içinde bulunduğu 31 OECD ülkesine ait veriler kümeleme analizine alınarak trafik kaza sayılarına göre hangi ülkelerin benzerlik gösterdiği ve kendi içinde homojen olan kümeler arasında istatistiksel olarak anlamlı bir farkın olup olmadığı belirlenmiştir.

\subsection{Kümeleme Analizi}

Gruplanmış verilerin benzerliklerine göre gruplandırmak istendiğinde kullanılan bir yöntem olan kümeleme analizi çok değişkenli analiz yöntemlerinden birisidir( Kalaycı, 2009: 349), Kümele analizinin en temel özelliklerinden bir tanesi kümelerin kendi içlerinde homojen aralarında ise heterojen olmasıdır. Bazı özellikleri açısından faktör analizine benzemesine rağmen, kümeleme analizinde değişkenler bağımlı ve bağımsız değişken olarak ayrılmamaktadır. Kümeleme analizi yapılırken aşağıdaki adımlar izlenir (Özdamar 2018:282).

1- Veri matrisinin elde edilmesi

2- Uzaklık/Benzerlik/Farklılık matrisini hesaplamak

3- Kümeleri belirlemek

4- Kümeleri irdelemek ve test etmek

\subsection{Analiz ve Bulgular}

2017 yılındaki OECD ülkelerinde trafik kazası sayılarına ait dağılım Tablo 1 de sunulmuştur. OECD veri tabanında yer almasına rağmen 2017 yılı için trafik kaza sayısı verilmemiş olan Slovak Cumhuriyeti Tablo 1 de sunulmuş ancak analize alınmamıştır.

Tablo 1. OECD Ülkelerinde Yaralanmalı Trafik Kazaları Sayısı

\begin{tabular}{|l|l|l|l|}
\hline OECD Ülkeleri & $\begin{array}{c}\text { Yaralanmalı Trafik } \\
\text { Kazası (n) }\end{array}$ & OECD Ülkeleri & $\begin{array}{c}\text { Yaralanmalı Trafik } \\
\text { Kazası (n) }\end{array}$ \\
\hline Avusturya & 5373 & Letonya & 2485 \\
\hline Belçika & 4258 & Litvanya & 1261 \\
\hline Şili & 3383 & Lüksemburg & 2131 \\
\hline Çek Cumhuriyeti & 2550 & Meksika & 810 \\
\hline Danimarka & 545 & Hollanda & 1197 \\
\hline Estonya & 1312 & Yeni Zelenda & 8752 \\
\hline Finlandiya & 1012 & Norveç & 930 \\
\hline Fransa & 1150 & Polonya & 1027 \\
\hline Almanya & 4722 & Portekiz & 4261 \\
\hline Yunanistan & 1232 & Slovenya & 3824 \\
\hline Macaristan & 2255 & Slovak Cum & 0 \\
\hline Izlanda & 3992 & İspanya & 2990 \\
\hline Israil & 2826 & İsveç & 1971 \\
\hline Italya & 4132 & İsviçre & 2534 \\
\hline Japonya & 4584 & Türkiye & 3717 \\
\hline Kore & 6275 & Birleşik Krallık & 2700 \\
\hline
\end{tabular}

Yukarıdaki bilgiler dikkate alınarak yapılan kümeleme analizi sonuçları Tablo 2 de sunulmuştur. 
Tablo 2. Yaralanmalı Trafik Kazalarına Göre Kümelenen OECD Ülkeleri

\begin{tabular}{|l|l|}
\hline Küme 1 & Küme 2 \\
\hline Avusturya & Şili \\
\hline Belçika & Çek Cumhuriyeti \\
\hline Almanya & Danimarka \\
\hline İzlanda & Estonya \\
\hline Italya & Finlandiya \\
\hline Japonya & Fransa \\
\hline Kore & Yunanistan \\
\hline Yenizelenda & Macaristan \\
\hline Portekiz & İsrail \\
\hline Slovanya & Letonya \\
\hline Türkiye & Litvanya \\
\hline & Lüksenburg \\
\hline & Meksika \\
\hline & Hollanda \\
\hline & Norveç \\
\hline & Polonya \\
\hline & İspanya \\
\hline & İsveç \\
\hline & İsviçre \\
\hline & Birleşik Krallık \\
\hline & \\
\hline & \\
\hline &
\end{tabular}

Tablo 2 incelendiğinde, kümeleme analizine göre yaralanmalı trafik kazasının söz konusu olduğu 31 OECD ülkesinin kendi içinde homojen, aralarında ise heterojen iki kümeye ayrıldığı bu ülkelerden yukarıdaki tabloda isimleri bulunan ve içinde Türkiye'nin de bulunduğu 11 ülkenin birinci kümede kalan 20 ülkenin ise ikinci kümede yer aldığg görülmektedir.

Her bir ülkenin başlangıçta tek başına bir küme olarak kabul edildiği, daha sonra benzerliklerine göre yeni birimlerin eklenmesi ile kümelerin birbirlerine bağlandığını gösteren dendogram adı verilen ağaç grafiği Şekil 1 de sunulmuştur. Kümeleme analizi yapıldıktan sonra trafik kaza sayılarına göre kümeler arasında istatistiksel olarak anlamlı bir fark olup olmadığının belirlenmesi için yapılan analiz sonuçları dendogramdan sonra verilerek kurulan hipotez test edilmiştir. 
Şekil 1. Dendogram

Dendrogram

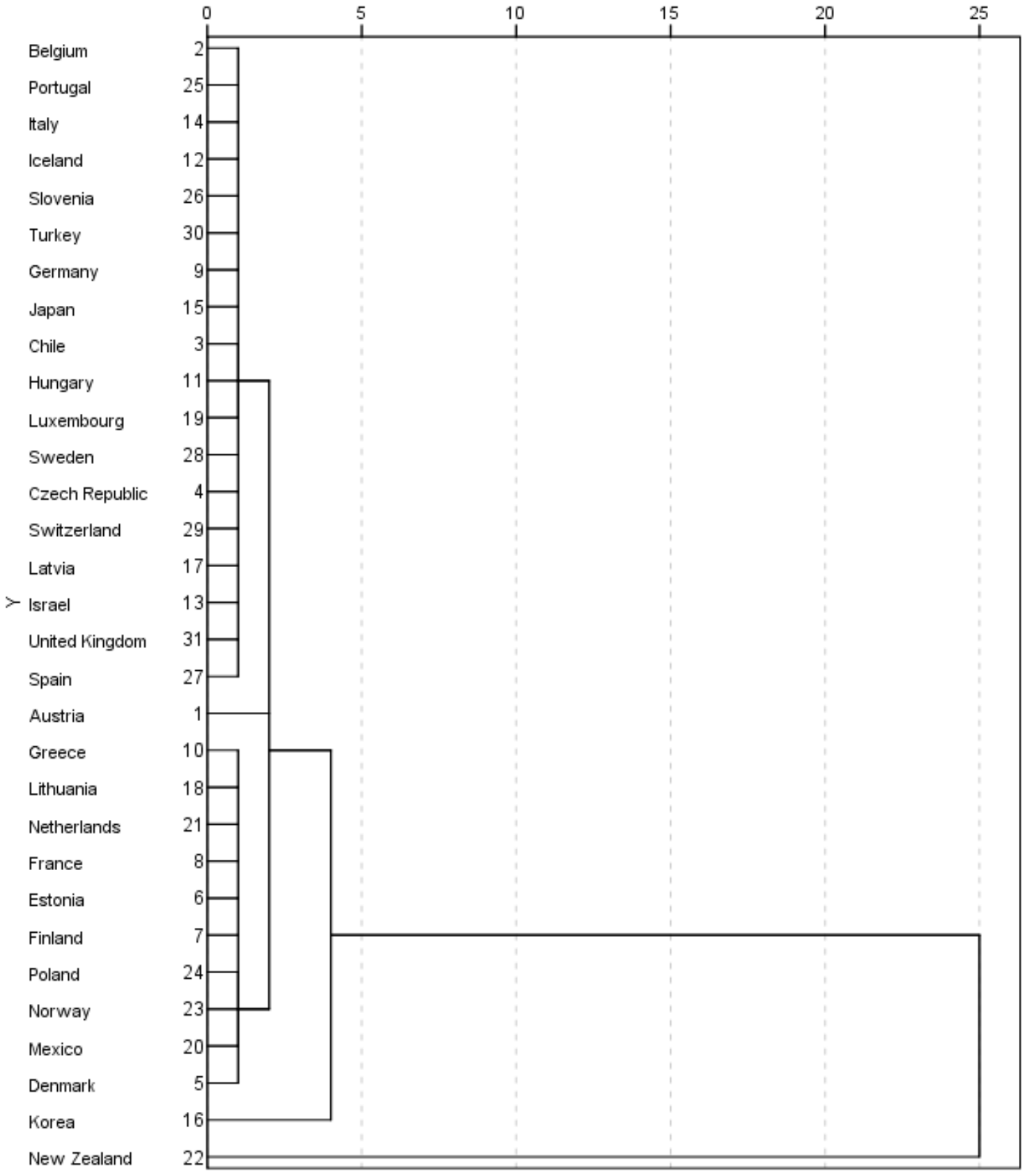

Varyans analizi ile kümeler arasında anlamlı bir farklılık olup olmadığına bakılmış ve hipotez aşağıdaki şekilde kurulmuştur.

$\mathrm{H}_{0}$ : Yaralanmalı trafik kazaları açısından kümeler arasında anlamlı bir farklılık yoktur.

$\mathrm{H}_{1}$ : Yaralanmalı trafik kazaları açısından kümeler arasında anlamlı bir farklılık vardır.

Analiz sonuçlarına göre; $F=55.992, \quad s d=30, p=0.000$ olarak çıkmış olup kümeler arasında yaralanmalı trafik kazası sayılarına göre anlamlı bir farklılık çıkmıştır. 


\section{SONUÇ:}

Trafik kazası bir ülke için hem devleti hem de toplumu ilgilendiren önemli bir konudur. Trafik kazalarının önlenmesi için yapılan hukuki ve toplumu bilinçlendirme çalışmaları her geçen gün artmaktadır. Bu çalışmaların doğru yapılması için trafik kazalarına yönelik akademik araştırmalar oldukça önemlidir. Konuya yönelik yapılan çalışmalarda ülkelerin gelişmişlik düzeyleri ile trafik kaza sayıları arasında önemli bir ilişki olduğu elde edilen sonuçlar arasında yer almaktadır. Bu amaçla bu çalışmada içinde Türkiye'nin de yer aldığ 1 bir 31 OECD ülkesi 2017 yılı yaralanmalı trafik kaza sayılarına göre kümeleme analizine alınmıştır. Yapılan analiz sonrasında bu ülkelerin 2 kümeye ayrıldığı görülmüştür. 1. kümede Avusturya, Belçika, Almanya, İzlanda, Italya, Japonya, Kore, Yenizelenda, Portekiz, Slovanya, ve Türkiye'ninde içinde bulunduğu 11 ülkeden oluşurken, 2. küme Şili, Çek Cumhuriyeti, Danimarka, Estonya, Finlandiya, Fransa, Yunanistan, Macaristan, İsrail, Letonya, Litvanya, Lüksenburg, Meksika, Hollanda, Norveç, Polonya, İspanya, İsveç, İsviçre, Birleşik Krallık olmak üzere 20 ülkeden oluşmuştur. Bu ülkelerin oluşturduğu kümeler arasındaki farklılığın istatistiksel olarak anlamlı olup olmadığına bakıldığında, farkın anlamlı olduğu görülmüştür. 


\section{KAYNAKÇA}

ALP S. ve ENGİN T. (2011), Trafik Kazalarının Nedenleri ve Sonuçları Arasındaki İlişkinin Topsis ve AHP yöntemleri Kullanılarak Analizi ve Değerlendirilmesi, İstanbul Ticaret Üniversitesi Fen Bilimleri Dergisi, 10(19): 65-87

EYGÜ H., (2018), Trafik Kazalarını Etkileyen Faktörlerin Yapısal Eşitlik Modeli İle İncelenmesi, Elektronik Sosyal Bilimler Dergisi, 17(66): 837-850

GEYMEN A. ve DEDEOĞLU O.,K., (2016), Coğrefi Bil Sistemlerinden Yaralanarak Trafik Kazalarının Azaltılması: Kahramanmaraş İli Örneği, Iğdır Üniversitesi Fen Bilimleri Enstitüsü Dergisi, 6(2): 79-88

GÖKHAN M. ve ATALAY A., (2015), Trafik Eğitiminin Trafik Kazaları Üzerindeki Etkisi, Fen Bilimleri Enstitüsü Dergisi, 8(2): 272-283

KALAYCI Ş.(2009), SPSS Uygulamalı Çok Değişkenli İstatistik Teknikleri, 4. Baskı, Asil Yayın, Ankara

ÖZDAMAR K. (2018), Paket Programlar ile İstatistiksel Veri Analizi Cilt II, 10. Bask1, Nisan Yayınevi, Eskişehir

ÖZDEN C. Ve ACI Ç. (2018), Makine Öğrenmesi Yöntemleri ile Yaralanmalı Trafik Kazalarının Analizi: Adana Örneği, Pamukkale Üniversitesi Mühendislik Bilimleri Dergisi, 24(2): 266-275

SUNGUR İ., AKDUR R. ve PIYAL B. (2014), Türkiye'de Trafik Kazalarının Analizi, Ankara Medical Journal, 14(3), 14(3):114-124

TERZİOĞLU Y. ve KAYA S. (2017), Ağır Taşıtların Karıştığı Ölümlü ve Yaralanmalı Trafik Kazalarının Değerlendirilmesi, Uluslararası Trafik ve Ulaşım Güvenliği Dergisi, 3(1):30-44

UYURCA Ö. ve ATILGAN İ., (2018), Ankara İlinde Meydana Gelen Trafik Kazalarının İncelenmesi, Kent Kültürü ve Yönetimi Hakemli Elektronik Dergi, 11(4):618-626

YURDAKUL A., TURAN D. ve ÇOMAKLI E., (2017), Kamusal Düzenleme Olarak Sürücü Belgesi Verilmesinin (Trafik Eğitiminin) Özel Kuruluşlara Devrinin Sosyo-Ekonomik Maliyetleri, Uluslararası Trafik ve Ulaşım Güvenliği Dergisi, 3(1):12-28 
ŞIMŞEK KANDEMIR / Yaralanmali Trafik Kaza Sayilarinin OECD Ülkelerine Göre Incelenmesi 